\title{
Regression of Hypermetabolic Splenic Granulomata Mimicking Metastases Following Non-targeted Effect of Radiotherapy for Uterine Cervical Carcinoma
}

\author{
(1) Nazmiye Deniz Arslan ${ }^{1}$, (1) Sedef Dağ ${ }^{1}$, (1) Ayşe Kutluhan Doğan ${ }^{1}$, (1) Nesrin Gürçay ${ }^{2}$, \\ (1) Hüseyin Özkurt ${ }^{3}$, (1) Burçak Yılmaz ${ }^{4}$
}

\begin{abstract}
${ }^{1}$ University of Health Sciences Turkey, Yedikule Chest Disease and Toracic Surgery Training and Research Hospital Clinic of Radiation Oncology, İstanbul, Turkey

${ }^{2}$ University of Health Sciences Turkey, Atatürk Chest Disease and Toracic Surgery Training and Research Hospital, Clinic of Pathology, Ankara, Turkey

${ }^{3}$ University of Health Sciences Turkey, İstanbul Şisli Hamidiye Etfal Training and Research Hospital, Clinic of Radiology, İstanbul, Turkey

${ }^{4}$ University of Health Sciences Turkey, Başakşehir Çam and Sakura City Hospital, Clinic of Nuclear Medicine, İstanbul, Turkey
\end{abstract}

\section{What is known on this subject?}

If there are any suspicious or atypical findings, histopathological verification is mandatory, and the treatment should be arranged accordingly.

\section{What this case report adds?}

The systemic effects of radiation therapy in nonirradiated area might influence active granulomatous reactions. Such effects have not been described in the literature before and needs further investigation.

\section{ABSTRACT}

Cervical carcinoma (CC) is one of the most common cancers in women. Unfortunately, false-positive imaging findings can be reported, which may change the treatment plans. In this case report, we describe a patient with CC and incidentally detected splenic lesions mimicking metastases, seen on magnetic resonance imaging, ultrasonography, and 2-( $\left.{ }^{18} \mathrm{~F}\right)$-fluoro-2-deoxy-D-glucose positron emission tomography/computed tomography. Histopathology confirmed a granulomatous infection. Although the patient did not receive any therapy for the infection, the splenic lesions almost disappeared on follow-up imaging, possibly due to the non-targeted immunological effect of radiation therapy.

Keywords: Cervical cancer, MRI, FDG-PET/CT, false positive, non-targeted effect

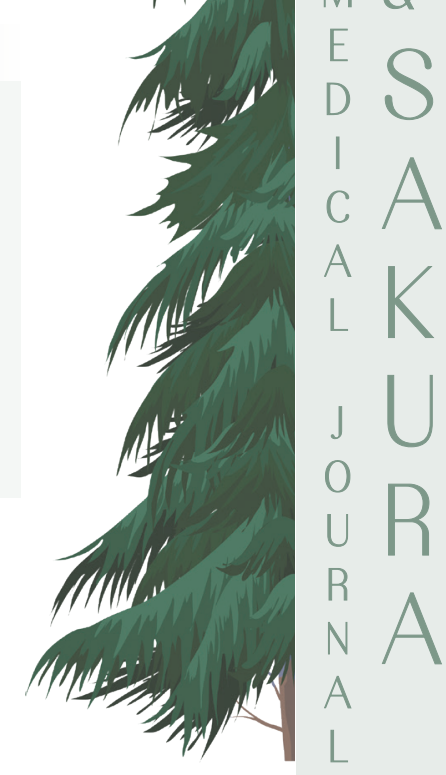

Address for Correspondence: Nazmiye Deniz Arslan MD, University of Health Sciences Turkey, Yedikule Chest Disease and Toracic Surgery Training and Research Hospital, Clinic of Radiation Oncology, İstanbul, Turkey

Phone: +90 5446681549 E-mail: denizsaracoglu@hotmail.com ORCID ID: orcid.org/0000-0003-0080-2284

Received: 02.02.2021 Accepted: 18.03.2021

(C) Copyright 2021 by the Cam \& Sakura Medical Journal published by Galenos Publishing House. 


\section{Introduction}

Despite using screening methods and vaccinations, cervical carcinoma (CC) is the third most common cancer and the leading cause of cancer-related death in women $(1,2)$. To understand the locoregional extension of the disease and pretreatment assessment of prognostic factors such as tumor diameter, parametrial invasion, and lymph node metastases, magnetic resonance imaging (MRI) is the preferred imaging modality $(3,4)$. For detecting distant metastases, 2-( $\left.{ }^{18} \mathrm{~F}\right)$-fluoro2-deoxy-D-glucose (FDG) positron emission tomography/ computed tomography (PET/CT) (1).

CC metastases tend to commonly occur through direct local invasion and lymphatic dissemination. Hematogenous metastases are infrequent and usually occur in advanced tumors or uncommon pathologic types (5). Common distant metastatic sites are lungs, bones, and liver (6). Splenic metastasis of squamous cell carcinoma of the uterine cervix is extremely rare $(7,8,9,10,11)$. In such rare cases, if a metastatic splenic lesion is suspected based on one imaging modality, then this can be further evaluated by other modalities for optimal staging and diagnosis and minimizing the rate of false-positive findings (12).

A non-targeted effect of radiation therapy (out-of-field tumor response, abscopal effect, and bystander effect) means that the localized irradiation induced systemic antitumorigenic effects, inducing shrinkage of a tumor distant from the radiation field (13). It is suggested that irradiated cells may start to affect nearby or distant non-irradiated cells (14).

In this case report, we present a patient with spleen lesions with false-positive findings on MRI, ultrasonography (USG), and ${ }^{18} \mathrm{~F}-\mathrm{FDG}-\mathrm{PET} / \mathrm{CT}$. This suggests CC metastases, with a near total regression of splenic lesions after radiation therapy without any anti-infectious treatment.

\section{Case Report}

A 52-year-old postmenopausal Syrian woman (height: $150 \mathrm{~cm}$; body weight: $53 \mathrm{~kg}$ ) presented to our hospital with abnormal vaginal bleeding and pelvic pain for one year. Previous medical and surgical history was negative. There was no family history of cancer. Her vital signs were normal. On the gynecological examination, a bulky cervical tumor extending into the upper vaginal wall with left parametrial invasion was observed. Colposcopy was planned, and cervical punch biopsies revealed moderately differentiated minimally keratinized large cell squamous cell carcinoma of the cervix (Figure 1). Her laboratory tests included the following: Leukocyte $12.15 \times 10^{\wedge} / \mathrm{uL}$ (4.5-10.5), neutrophil $8.51 \times 10^{\wedge} /$
uL (1.56-6.13), hemoglobin $10.2 \mathrm{~g} / \mathrm{dL}$ (11.5-15.5), c reactive protein $10.35 \mathrm{mg} / \mathrm{L}(0-5)$, parathormone $568.6 \mathrm{pg} / \mathrm{mL}$, calcium $8.53 \mathrm{mg} / \mathrm{dL}$ (8.6-10.2), phosphor $2 \mathrm{mg} / \mathrm{dL}$ (2.6-4.5), and 25- $\mathrm{-H}$ vitamin $\mathrm{D}<3.0 \mathrm{ng} / \mathrm{mL}$. Brucella agglutination test and tumor markers including CEA, CA-125, and CA 15-3 were negative.

For evaluating the locoregional extension of the disease, the patient underwent abdominopelvic MRI with intravenous gadolinium-diethylenetriamine-pentaacetic acid contrast agent. On MRI, there was a $53 \mathrm{~mm}$ mass in the uterine cervix with extension into the urinary bladder anteriorly and rectum posteriorly, in addition to multiple right iliac, left paraaortic, and mesenteric enhancing lymph nodes. Incidentally detected on MRI were widespread splenic lesions, which were hypointense on T2 weighted images without contrast enhancement. Because of the clinical history of a known malignancy, the lesions in the spleen were interpreted as suspicious of metastases (Figure 2).

${ }^{18} \mathrm{~F}-\mathrm{FDG}$-PET/CT scan was then performed for evaluating the distant metastatic disease. In the uterine cervix, the known mass had a maximum standardized uptake value $\left(\mathrm{SUV}_{\max }\right)$ of 24.5. There were multiple FDG-avid metastatic lymph nodes with SUV ${ }_{\max }$ up to 3.6, seen in the paraaortocaval, bilateral iliac chain, and bilateral parametrial regions. PET/CT also demonstrated widespread heterogeneously hypermetabolic lesions with SUV max $_{\text {ax }}$ of 13.0 in the spleen (Figure 3).

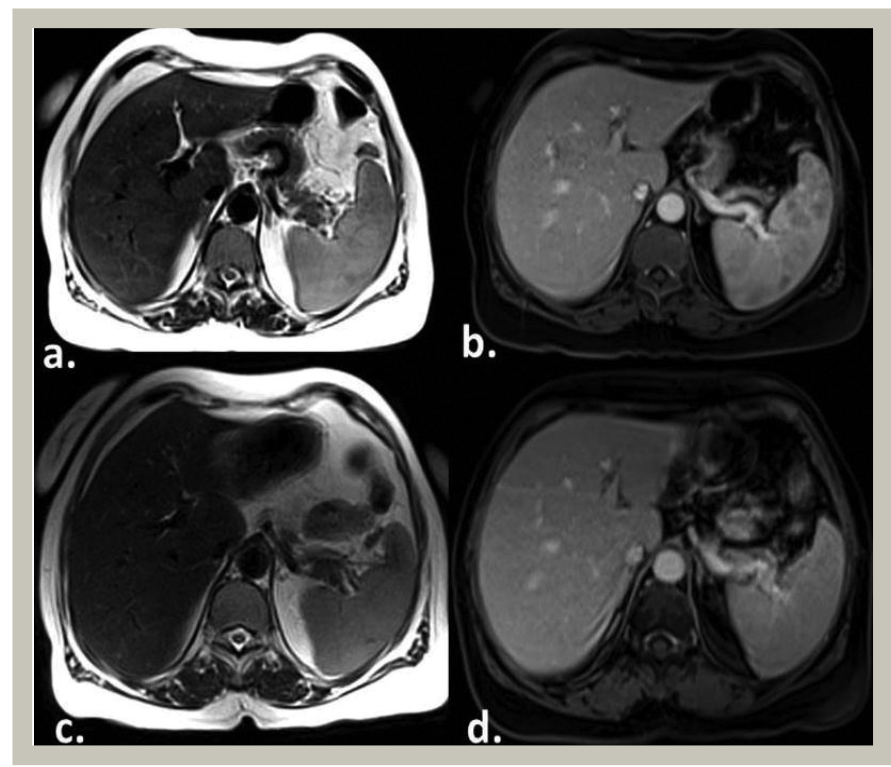

Figure 1. a) Squamous cell carcinoma of the uterine cervix infiltrating stroma with a significant pleomorphism (HE, 10X). b) Minimal caseification and necrosis in the center and epithelioid histiocytes and multinucleated giant cells in the surrounding of granuloma in spleen parenchyma (H\&E, 200X)

H\&E: Heosin and eosin 


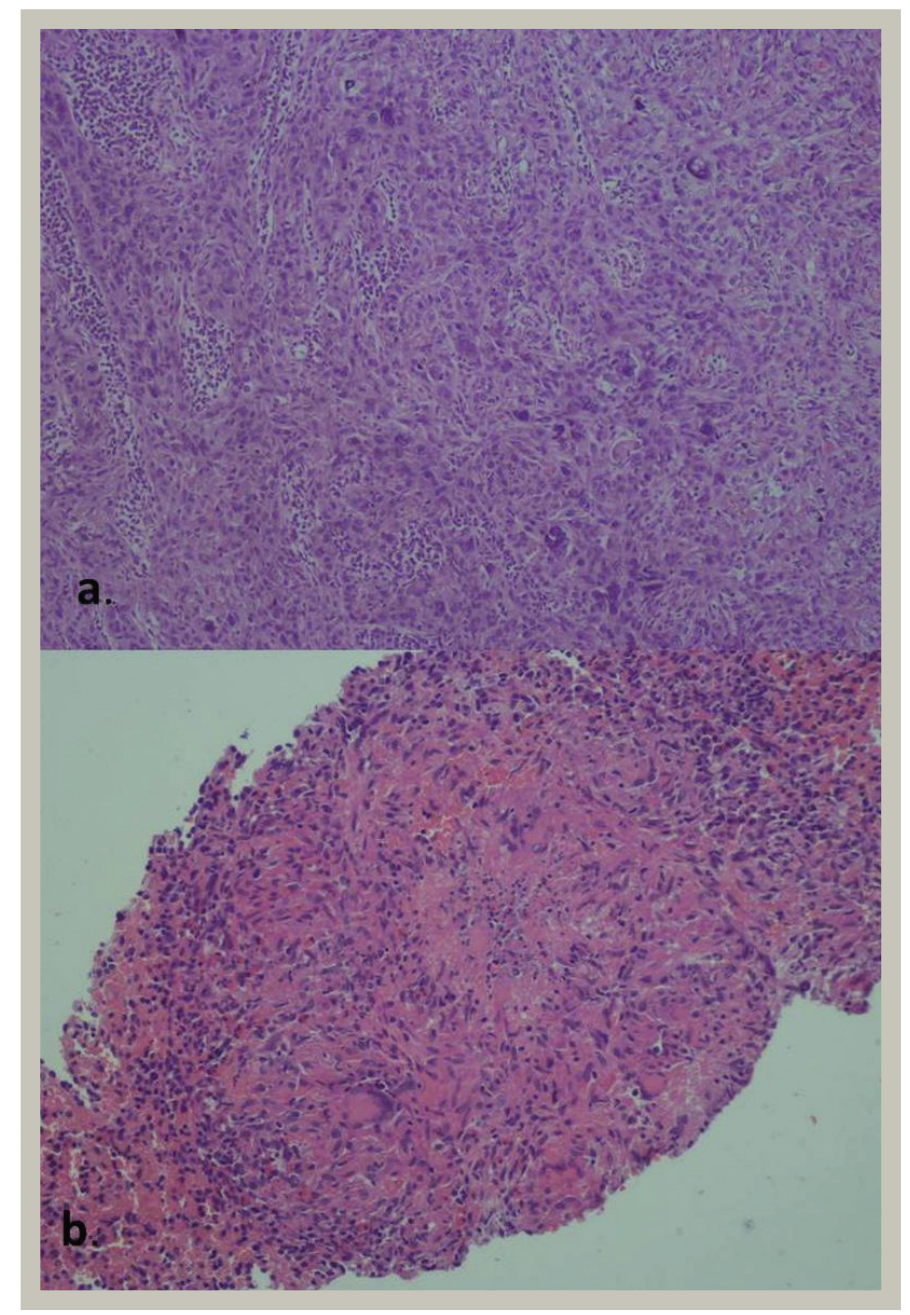

Figure 2. a) Pretreatment axial T2-weighted MR image demonstrates slightly hypointense multiple lesions, significant in the anterior spleen parenchyma. b) Pretreatment axial postcontrast T1-weighted image demonstrates hypointense multiple lesions. C, d) Axial T2-weighted and axial postcontrast T1-weighted images three months after radiation therapy demonstrate significant regression of spleen lesions

MR: magnetic resonance

With the suspicion of splenic metastases, USG guided biopsy was planned. USG detected hypoechoic lesions with fuzzy contours in some lesions of the spleen. A tru-cut biopsy was performed. Histopathology was consistent with granuloma without any neoplasm subsequently (Figure 1).

Following the imaging and laboratory tests, the disease was classified as stage IIB according to the International Federation of Gynecology and Obstetrics staging system. The treatment plan was concurrent chemotherapy and whole-pelvic and paraaortic FDG-PET/CT-based external beam radiation therapy (EBRT) followed by 3D-image-guided high-dose-rate intracavitary radiation therapy (3D-HDR-ICRT). The patient received weekly cisplatin $\left(40 \mathrm{mg} / \mathrm{m}^{2}\right)$ with premedication (steroid and antiemetic) and 50.4 Gy EBRT to the pelvis in 28 fractions following paraaortic field radiotherapy with a dose of $45 \mathrm{~Gy}$ in daily fractions of $1.8 \mathrm{~Gy}$.

Three months after radiation therapy, ${ }^{18} \mathrm{~F}-\mathrm{FDG} / \mathrm{PET}$ and MRI were performed to evaluate the treatment effects. ${ }^{18} \mathrm{~F}-\mathrm{FDG} /$ PET imaging detected residual FDG-avid disease in the left side of the uterine cervix with SUV max $_{\text {m }}$ of 5.0 and decreased size and FDG activity within the lymph nodes described on the initial PET/CT with SUV ${ }_{\text {max }}$ up to 1.2, previously 3.6. There was no abnormal FDG uptake in the spleen (Figure 3). On $\mathrm{MRI}$, residual cervical tumoral lesions with decreased size and subcentimetric iliac chain lymph nodes were reported, with the regression of the splenic lesions (Figure 2). At the start of the initial therapy, the patient did not receive any treatment for infection. After the follow-up examinations, adjuvant chemotherapy was planned.

\section{Discussion}

A detailed analysis of previous imaging and clinical history and a multidisciplinary approach of clinicians and experienced radiologists/nuclear medicine physicians help decide which further investigations should be performed for an exact diagnosis in suspicious conditions (15).

In CC, the most common sites of metastases are the lungs, bones, liver, supraclavicular nodes, and paraaortic nodes (5). Uncommon metastatic sites of CC have been reported in the skin and soft tissue (16), breast (7), pericardium (17), umbilical region (18), vulva (19), thyroid gland (20), oral cavity (21), skeletal muscle (22), intestine (5), ovaries (23), brain (24), and spleen $(7,8,9,10,11)$. Uterine $C C$ is a rare source of splenic metastasis. Splenic metastases of squamous cell carcinoma of the cervix have been reported to be $15.3 \%$ of distant metastasis (25).

When splenic metastasis is detected, surgery is not indicated (11). Our patient had paraaortic lymph node metastases with a locoregional extension of the disease. In this clinical setting, the presence of multiple splenic lesions has been interpreted as metastatic, with knowledge of its rarity. The clinicians were aware that the patient came from a war zone, with limited resources for self-hygiene, and they highly suspected an underlying infectious process. Therefore, USG-guided biopsy of the splenic lesions was performed for therapy planning. The pathology was consistent with granuloma. Similar to our patient, many infectious agents involve the spleen, such as pyogenic abscess, fungal abscess, parasitic disease, and granulomous infections (26). 


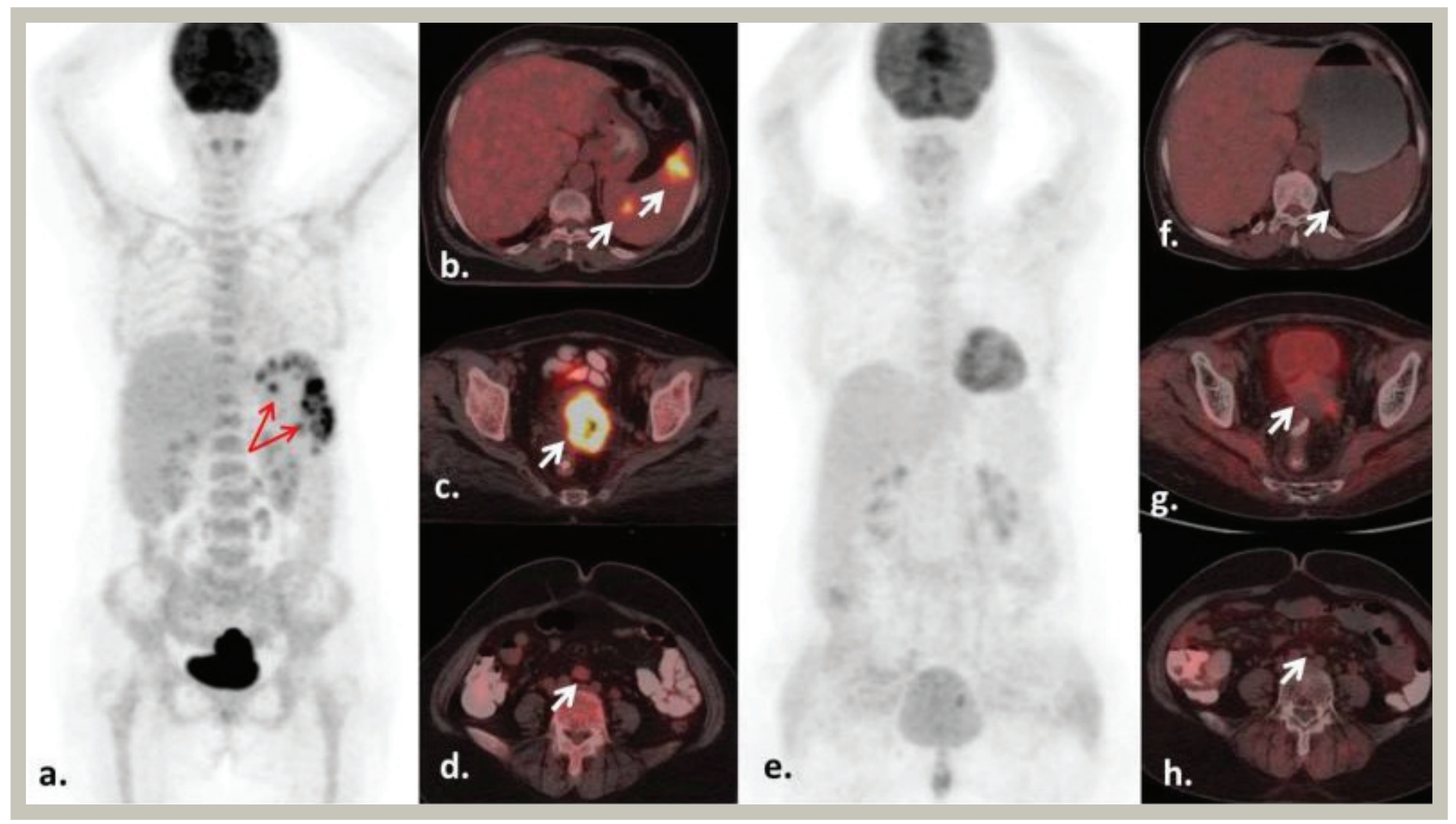

Figure 3. Pretreatment FDG-PET/CT images. a) MIP image showing multiple hypermetabolic spleen lesions. b) Fusion axial PET/CT image showing hypermetabolic spleen lesions. c) Fusion axial PET/CT image showing hypermetabolic primary uterine cervix carcinoma. d) Fusion axial PET/CT image showing slightly hypermetabolic paraaortic metastatic lymph node. FDG-PET/CT images three months after radiation therapy. e) MIP image showing no abnormal FDG uptake in the spleen. $f$ ) Fusion axial PET/CT image showing total regression of hypermetabolic splenic lesions. g) Fusion axial PET/CT image showing slightly hypermetabolic residual tumoral lesion on the left side of the uterine cervix. h) Fusion axial PET/CT image demonstrating metabolic and anatomical regression of mildly hypermetabolic paraaortic metastatic lymph node

FDG: 2-(18F)-fluoro-2-deoxy-D-glucose, MIP: Maximum intensity projection, PET/CT: Positron emission tomography/computed tomography

Concerning ${ }^{18} \mathrm{~F}-\mathrm{FDG}-\mathrm{PET} / \mathrm{CT}$, FDG uptake is not only seen in malignancy but also in infection and inflammation, due to increased glucose metabolism. False-positive FDG uptake has been reported in abscesses, postsurgical changes, granulomatous diseases, foreign body reactions, diverticulitis, gastritis, and arteriosclerosis (27). More than 25\% of PET/CT studies in patients with cancer have been declared to estimate a non-physiological benign FDG uptake. Almost 50\% of incidentally detected foci of FDG uptake outside the primary region of the tumor area are related to benign pathological situations, unrelated to the primary tumor $(28,29)$.

Conversely, USG is cheap and easily accessible, but inferior to MRI for detection of focal lesions (30). However, MRI have some drawbacks; periportal eosinophilic infiltration, abscess, granuloma, and peripheral edema due to parasitic infiltration may cause small, ill-defined, oval or elongated nodules on dynamic images similar to other types of granuloma or inflammatory lesions (31).

In our patient, the infectious agent was unidentified, and she did not get any specific therapy for infection. Surprisingly, on the follow-up examinations, splenic lesions have had almost resolved. The patient only received concurrent chemoradiotherapy. Systemic chemotherapy with steroid premedication induces immunosuppression. Therefore, theoretically, it should have caused worsening of the infectious process. Another possible explanation is that the patient had an atypical form of sarcoidosis, with isolated splenic involvement. This explanation is also unlikely as chemotherapy usually causes flaring of sarcoidosis. One possible explanation is an interval improvement in an infectious process due to the "non-targeted effect of radiation therapy", which suggests that local radiotherapy initiates 
and promotes systemic immunological responses $(14,32)$. This effect is still under investigation; several potential mechanisms are possible, including distant effects on p53, elaboration of inflammatory agents including cytokines, and secondary immune mechanisms (33). After total abdominal or total-body irradiation of mice, the radiation-induced systemic inflammatory reaction and cytokine and chemokine production were increased (34). In our patient, the splenic non-metastatic lesions resolved after radiation therapy, without any anti-infectious treatment. From this perspective, we hypothesize that systemic effects of radiation therapy in non-irradiated area might influence active granulomatous reactions. Such effects have not been described in the literature before and needs further investigation.

Knowledge of patients' clinical status and key facts in their medical and social history and careful evaluation of imaging findings will increase the diagnostic confidence of radiologists and nuclear medicine physicians and help avoid misinterpretation. Multimodality imaging is preferred to make specific diagnoses. Different imaging modalities can be complimentary and may help clinicians in therapy planning. Awareness of pitfalls that can cause false-positive imaging findings, like in our patient, may prevent inappropriate patient management. In such patients, if there are any suspicious or atypical findings, histopathological verification is mandatory. Besides, non-targeted systemic effects of radiation therapy may induce anti-inflammatory response in non-irradiated area. However, this speculation needs further prospective research.

\section{Ethics}

Informed Consent: Patient consent has been obtained

Peer-review: Internally peer-reviewed.

\section{Authorship Contributions}

Surgical and Medical Practices: S.D., N.D.A., N.G., A.K.D., B.Y., Concept: S.D., N.D.A., Design: S.D., N.D.A., Data Collection or Processing: N.D.A., N.G., A.K.D., H.Ö., Analysis or Interpretation: B.Y., Literature Search: S.D., N.D.A., Writing: N.D.A.

Conflict of Interest: No conflict of interest was declared by the authors.

Financial Disclosure: The authors declared that this study received no financial support.

\section{REFERENCES}

1. Khan SR, Rockall AG, Barwick TD. Molecular imaging in cervical cancer. Q J Nucl Med Mol Imaging 2016;60:77-92.

2. Jemal A, Bray F, Center MM, Ferlay J, Ward E, Forman D. Global cancer statistics. CA Cancer J Clin 2011;61:69-90.

3. Thomeer MG, Gerestein C, Spronk S, van Doorn HC, van der Ham E, Hunink MG. Clinical examination versus magnetic resonance imaging in the pretreatment staging of cervical carcinoma: systematic review and meta-analysis. Eur Radiol 2013;23:20052018.

4. Miccò M, Vargas HA, Burger IA, et al. Combined pre-treatment MRI and 18F-FDG PET/CT parameters as prognostic biomarkers in patients with cervical cancer. Eur J Radiol 2014;83:1169-1176.

5. Yu X, Wang Z, Zhang Z, Liu Y, Huang J. Postoperation of cervical cancer with intestine metastasis: a case report and literature review. World J Surg Oncol 2016;14:2.

6. Nartthanarung A, Thanapprapasr K, Udomsubpayakul U, Thanapprapasr D. Age and survival of cervical cancer patients with bone metastasis. Asian Pac J Cancer Prev 2014;15:8401-8404.

7. Aitelhaj M, Khoyaali SL, Boukir A, et al. Breast and splenic metastases of squamous cell carcinoma from the uterine cervix: a case report. J Med Case Rep 2014;8:359.

8. Goktolga U, Dede M, Deveci G, Yenen MC, Deveci MS, Dilek S. Solitary splenic metastasis of squamous cell carcinoma of the uterine cervix: a case report and review of the literature. Eur J Gynaecol Oncol 2004;25:742-744.

9. Pang LC. Solitary recurrent metastasis of squamous cell carcinoma of the uterine cervix in the spleen: case report. South Med J 2004;97:301-304.

10. Brufman G, Biran S, Goldschmidt Z, Freund U. Solitary metastatic involvement of the spleen in squamous cell carcinoma of the cervix. Harefuah 1977;92:349-350.

11. Taga S, Sawada M, Nagai A, Yamamoto D, Hayase R. Splenic metastasis of squamous cell carcinoma of the uterine cervix: a case report and review of the literature. Case Rep Obstet Gynecol 2014;2014:798948.

12. Gunes BY, Özvar FH, Demirci E, Özkurt H, Baytekin HF, Kabuli H. Parasitic infestation mimicking hepatic metastasis with four different imaging modalities in a patient with breast carcinoma. Breast J 2017;23:468-470.

13. Cong Y, Shen G, Wu S, Hao R. Abscopal regression following SABR for non-small-cell-lung cancer: a case report. Cancer Biol Ther 2017;18:1-3.

14. Sun R, Sbai A, Ganem G, et al. Effets non ciblés (bystander, abscopal) de la radiothérapie externe: potentielles implications pour le clinicien ? [non-targeted effects (bystander, abscopal) of external beam radiation therapy: an overview for the clinician]. Cancer Radiother 2014;18:770-778. 
15. Culverwell AD, Scarsbrook AF, Chowdhury FU. False-positive uptake on 2-[18 F]-fluoro-2-deoxy-D-glucose (FDG) positron-emission tomography/computed tomography (PET/CT) in oncological imaging. Clin Radiol 2011;66:366-382.

16. Mehrotra S, Singh U, Gupta HP, Saxena P. Cutaneous metastasis from cervical carcinoma: an ominous prognostic sign. J Obstet Gynaecol 2010;30:78-79.

17. Kim HS, Park NH, Kang SB. Rare metastases of recurrent cervical cancer to the pericardium and abdominal muscle. Arch Gynecol Obstet 2008;278:479-482.

18. Behtash N, Mehrdad N, Shamshirsaz A, Hashemi R, Amouzegar Hashemi F. Umblical metastasis in cervical cancer. Arch Gynecol Obstet 2008;278:489-491.

19. Richmond NA, Viera MH, Velazquez-Vega J, Kerdel FA. Cutaneous metastasis of cervical adenocarcinoma to the vulva. Dermatol Online J 2013;19:18172.

20. Karapanagiotou E, Saif MW, Rondoyianni D, et al. Metastatic cervical carcinoma to the thyroid gland: a case report and review of the literature. Yale J Biol Med 2006;79:165-168.

21. Ram H, Kumar M, Bhatt ML, Shadab M. Oral metastases from carcinoma of cervix. BMJ Case Rep 2013;2013:bcr2013010020.

22. Ferrandina G, Salutari V, Testa A, Zannoni GF, Petrillo M, Scambia $G$. Recurrence in skeletal muscle from squamous cell carcinoma of the uterine cervix: a case report and review of the literature. BMC Cancer 2006;6:169.

23. Nakanishi T, Wakai K, Ishikawa $\mathrm{H}$, et al. A comparison of ovarian metastasis between squamous cell carcinoma and adenocarcinoma of the uterine cervix. Gynecol Oncol 2001;82:504-509.

24. Park SH, Ro DY, Park BJ, et al. Brain metastasis from uterine cervical cancer. J Obstet Gynaecol Res 2010;36:701-704.

25. Carlson V, Delclos L, Fletcher GH. Distant metastases in squamouscell carcinoma of the uterine cervix. Radiology 1967;88:961-966.
26. Thipphavong S, Duigenan S, Schindera ST, Gee MS, Philips S. Nonneoplastic, benign, and malignant splenic diseases: crosssectional imaging findings and rare disease entities. AJR Am J Roentgenol 2014;203:315-322.

27. Sahani DV, Samir AE. Abdominal imaging: expert radiology series. pp 136-145.

28. Metser U, Miller E, Lerman H, Even-Sapir E. Benign nonphysiologic lesions with increased 18F-FDG uptake on PET/CT: characterization and incidence. AJR Am J Roentgenol 2007;189:1203-1210.

29. Beatty JS, Williams HT, Aldridge BA, et al. Incidental PET/CT findings in the cancer patient: how should they be managed? Surgery 2009;146:274-281.

30. Vlachos L, Trakadas S, Gouliamos A, et al. Comparative study between ultrasound, computed tomography, intra-arterial digital subtraction angiography, and magnetic resonance imaging in the differentiation of tumors of the liver. Gastrointest Radiol 1990;15:102-106.

31. Lundstedt C, Ekberg H, Hederstrom E, Stridbeck H, Torfason B, Tranberg KG. Radiologic diagnosis of liver metastases in colorectal carcinoma. Acta Radiol 1987;28:431-438.

32. Weichselbaum RR, Liang H, Deng L, Fu YX. Radiotherapy and immunotherapy: a beneficial liaison? Nat Rev Clin Oncol 2017; $14: 365-379$

33. Lock M, Muinuddin A, Kocha WI, Dinniwell R, Rodrigues G, D'souza D. Abscopal effects: case report and emerging opportunities. Cureus 2015;7:e344.

34. Van der Meeren A, Monti P, Vandamme M, Squiban C, Wysocki J, Griffiths N. Abdominal radiation exposure elicits inflammatory responses and abscopal effects in the lungs of mice. Radiat Res 2005;163:144-152. 